\title{
Prevalência da infecção pelo vírus da hepatite $B$ em um município do interior do estado do Acre, Amazônia Ocidental, Brasil
}

\section{Prevalence of hepatitis B virus infection in a municipality of Acre State, Western Amazonia, Brazil}

Rita do Socorro Uchôa da Silva',2, Isadora Oliveira Morais², Danielly Moreira Gonçalves', Irenilce Souza de Matos', Francileide Ferreira da Rocha', Glivia Maria do Nascimento Torres', Maria Lucimar Almeida da Costa', Sueli Santiago da Silva', Paula Alessandra Martins da Silva', Renata Souza'

' Secretaria de Saúde do Estado do Acre, Rio Branco, Acre, Brasil

2 Universidade Federal do Acre, Centro de Ciências da Saúde e Desporto, Rio Branco, Acre, Brasil

\begin{abstract}
RESUMO
OBJETIVO: Estimar a prevalência do vírus da hepatite B (HBV) em indivíduos residentes no município de Porto Acre, estado do Acre, Amazônia Ocidental brasileira. MATERIAIS E MÉTODOS: Estudo transversal, no qual foram incluídos moradores que compareceram por livre demanda às unidades básicas de saúde de Porto Acre, em 2012, aos quais se aplicou questionário padronizado e se coletou sangue venoso. Como triagem, usou-se teste rápido imunocromatográfico para hepatite $B(\mathrm{HBsAg})$ e, diante do resultado reagente, foram realizados exames sorológicos ( $\mathrm{HBsAg}$ e anti-HBc total). Os marcadores $\mathrm{HBeAg}$, anti-HBe e anti-HD total foram utilizados exclusivamente nas amostras cujo HBsAg manteve-se reagente na sorologia. RESULTADOS: Foram incluídas 646 pessoas $(4,7 \%$ da população), sendo $57,6 \%$ do gênero feminino. Dezessete pessoas $(2,6 \%)$ obtiveram testes rápidos reagentes para - $\mathrm{HBsAg}$, dos quais em $82,3 \%$ (14/17) houve confirmação sorológica. $\mathrm{O}$ anti-HBc total foi reagente em $31,9 \%$ (206/646) dos indivíduos, dos quais 2,2\% (14/646) com HBV atual e 29,7\% (192/646) somente com evidência de infecção pregressa. Das $184(28,5 \%)$ crianças e adolescentes incluídos na pesquisa, 9,2\% (17/184) apresentaram contato prévio com o HBV. A ingestão abusiva de álcool apresentou correlação com reatividade ao $\mathrm{HBsAg}$ e ao anti- $\mathrm{HBc}$ total, enquanto faixa etária mais avançada, gênero masculino, cirurgias prévias e presença de tałuagens foram relacionados exclusivamente à maior reatividade ao anti-HBc total. CONCLUSÃO: A prevalência da infecção pelo HBV em Porto Acre evidencia a gravidade da situação, visto que um terço da amostra do estudo já entrou em contato com o vírus, valor provavelmente subestimado, dado que $28,5 \%$ foi composta por crianças e adolescentes que, normalmente, são grupos menos acometidos.
\end{abstract}

Palavras-chave: Hepatite Viral Humana; Vírus da Hepatite B; HBsAg; Anti-HBc Total.

\section{ABSTRACT}

OBJECTIVE: To estimate the prevalence of hepatitis B virus (HBV) in individuals living in Porto Acre municipality, Acre State, Western Brazilian Amazon. MATERIALS AND METHODS: Cross-sectional study carried out with residents of Porto Acre who had attended the basic health units in 2012 were invited to answer a standardized questionnaire and to donate venous blood. As screening, immunochromatographic rapid test (IRT) for hepatitis $B$ ( $\mathrm{HBsAg}$ ) was used, and from whom that was reagent to the IRT, serological tests ( $\mathrm{HBsAg}$ and total anti-HBc) were performed. The $\mathrm{HBeAg}$, anti-HBe and total anti-HD markers were used exclusively in the samples whose $\mathrm{HBsAg}$ remained serologically reagent. RESULTS: It was included 646 individuals (4.7\% of the population), $57.6 \%$ of the female gender. Seventeen individuals (2.6\%) were reagent to the IRT for HBsAg and of which in $82.3 \%(14 / 17)$ presented serological confirmation. Total anti-HBc was reactive in $31.9 \%(206 / 646)$ of the subjects, of which $2.2 \%$ (14/646) had current HBV and 29.7\% (192/646) only evidence of previous infection. Of the 184 (28.5\%) children and adolescents included in this study, 9.2\% (17/184) had prior contact with HBV. The abusive alcohol intake is correlated to $\mathrm{HBsAg}$ and total anti-HBc reactivity, whereas older age, male gender, previous surgeries, and the presence of tattoos were related exclusively to total anti-HBc higher reactivity. CONCLUSION: HBsAg seroprevalence was $2.2 \%$ and total anti-HBc approximately $32.0 \%$. There was detection of total anti-HBc in $9.2 \%$ of the children and adolescents included in the study, evidencing early contact with HBV in this population.

Keywords: Human Viral Hepatitis; Hepatitis B virus; HBsAg; Total Anti-HBc.

\footnotetext{
Correspondência / Correspondence:

Rita do Socorro Uchôa da Silva

Rua Vênus, 478. Bairro: Morada do Sol - CEP: 69901-100 - Rio Branco, Acre, Brasil - Tel.: +55 (68) 99971-8028

E-mail: rita.uchoa.acre@gmail.com
} 


\section{INTRODUÇÃO}

A hepatite B é um grande problema de saúde pública mundial, pois estima-se que mais de 2 bilhões de pessoas possuam evidência sorológica de infecção presente ou passada pelo vírus da hepatite $B(\mathrm{HBV})^{1,2}$, das quais 240 milhões mantêm-se como portadores de hepatite B crônica $^{2,3}$, com possibilidades de desenvolver complicações como cirrose hepática ou hepatocarcinoma ${ }^{4,5}$.

Em 2010, um estudo ${ }^{6}$ de base populacional avaliou a prevalência de hepatites virais em 26 capitais e no Distrito Federal, incluindo indivíduos na faixa etária de 10 a 69 anos, o qual evidenciou soroprevalência global de 7,4\% para o anti-HBc total, alcançando 10,9\% no grupo das capitais da Região Norte do país. Com relação ao marcador $\mathrm{HBsAg}$, a prevalência global para o conjunto das capitais foi de $0,37 \%$, porém atingindo $0,63 \%$ nas capitais nortistas. Segundo os autores, a principal limitação desse estudo foi a exclusão de populações que residiam em áreas onde as condições econômicas e de saúde eram mais críticas, como os municípios do interior, já que estudar somente as capitais e o Distrito Federal pode ter contribuído para dados subestimados de prevalência da infecção pelo HBV.

Na década de 1970, em Lábrea, estado do Amazonas, Bensabath e Boshel $^{7}$ identificaram cerca de $70 \%$ de soropositividade ao anti-HBc total e 15\% ao $\mathrm{HBsAg}$ na população. Foi implantado, nesse município, o programa de vacinação contra o HBV, e, 19 anos depois, Braga et al. ${ }^{8}$ evidenciaram mais de $50 \%$ da população com reatividade anti-HBc total e apenas 6,2\% ao $\mathrm{HBsAg}$, concluindo que, apesar de ter havido redução nos índices, a infecção pelo HBV mantém-se como um grande problema de saúde pública a ser vencido nas zonas rurais da Amazônia.

No estado do Pará, Aquino et al. ${ }^{9}$, usando uma amostra de conveniência de indivíduos que buscaram - Laboratório Central de Saúde Pública (Lacen) do Pará, no período de 2002 a 2005, para a realização de exames, encontraram soropositividade de 3,6\% para - $\mathrm{HBsAg}$ e $37,7 \%$ para o anti-HBc total. Em crianças de 0 a 9 anos de idade, a reatividade ao $\mathrm{HBsAg}$ foi de $2,2 \%$

Estudos realizados no estado do Acre indicaram que a prevalência do HBV na população tem variado de 40,2 a 61,5\%10,11,12. Há estudos que detectaram reatividade de 3,3\% ao $\mathrm{HBsAg}$ na população acreana ${ }^{10,12}$, havendo comprovação de transmissão intrafamiliar do vírus correlacionada ao compartilhamento de objetos de uso pessoal, como escovas de dentes ${ }^{13}$.

Carcinoma hepatocelular consiste em uma das consequências da infecção crônica pelo HBV e, segundo Nakashima et al. ${ }^{14}$, as taxas de mortalidade por neoplasia maligna do fígado e vias biliares, no período de 2002 a 2006, na capital acreana, foram de 11,7/100.000 no sexo masculino e de 6,7/100.000 no feminino.
Este estudo foi desenvolvido no intuito de estimar a prevalência do HBV na população do município acreano de Porto Acre, podendo contribuir para a detecção precoce da infecção ativa pelo HBV e para - acompanhamento especializado dos indivíduos acometidos por esse vírus.

\section{MATERIAIS E MÉTODOS}

Realizou-se um estudo transversal durante o ano de 2012, no município acreano de Porto Acre, o qual dista cerca de $50 \mathrm{~km}$ de Rio Branco, capital do Estado e, em 2009, apresentava uma população de 13.716 habitantes $^{15}$.

Foram realizados atendimentos em voluntários, moradores de Porto Acre, que compareceram a três centros de saúde pertencentes ao município Sede, Vila do Incra e Vila do "V". Visando estimar a prevalência da infecção ativa pelo HBV, calculou-se o tamanho mínimo da amostra em 494 pessoas (Epi InfoTM - Statcalc) da população municipal, com prevalência de 3,3\% de casos de infecção pelo HBV, percentual detectado em outros estudos no Acre ${ }^{10,12}$; o erro admitido foi de $5 \%$, além de ter sido feita inclusão de $20 \%$ a mais de indivíduos, devido à possibilidade de perdas durante o processo de coleta de dados.

Previamente, realizou-se, em Porto Acre, ampla divulgação sobre a pesquisa pelos agentes comunitários de saúde e pela rádio local. Os habitantes do Município foram convidados a comparecer como voluntários para serem submetidos à aplicação de um questionário clínico-epidemiológico e à realização de exames para hepatite $\mathrm{B}$ : teste rápido por imunocromatografia $\mathrm{HBsAg}$ $\left(\right.$ WAMA ${ }^{\circledR}$, Brasil) e quimioluminescência Architect $^{\circledR}$, Brasil) $\mathrm{HBsAg}$ e anti-HBc total; os reagentes ao $\mathrm{HBsAg}$ foram submetidos aos testes $\mathrm{HBeAg}$ (Architect ${ }^{\circledR}$, Brasil), anti-HBe (Architect ${ }^{\circledR}$, Brasil) e anti-HD (Dia Sorin ${ }^{\circledR}$, Brasil).

Coletou-se sangue venoso de todos os voluntários, que foram testados para o marcador sorológico de contato prévio com o $\mathrm{HBV}$, o anti-HBc total, e pelo teste rápido $\mathrm{HBsAg}$ por imunocromatografia. Os indivíduos reativos ao $\mathrm{HBsAg}$ por imunocromatografia foram também testados pelo teste $\mathrm{HBsAg}$ por quimioluminescência. Diante de amostras que resultaram em teste rápido $\mathrm{HBsAg}$ reagente e por quimioluminescência não reagente, houve submissão à quimioluminescência para anti-HBs; tendo o mesmo resultado não reagente, realizou-se HBV-DNA quantitativo. Os indivíduos identificados como portadores da infecção pelo HBV foram atendidos no próprio Município por profissionais especializados e referenciados ao serviço médico no Serviço de Atendimento Especializado (SAE) de Rio Branco. Usou-se o programa SPSS v20.0 para análise dos dados.

$\bigcirc$ projeto foi aprovado pelo Comitê de Ética em Pesquisa em Seres Humanos da Fundação Hospital Estadual do Acre, com o título "Panorama da hepatite B no município de Porto Acre", em 28 de setembro de 2010, sob parecer $n^{\circ}$ 043/2010. 


\section{RESULTADOS}

Foram incluídas 646 pessoas no estudo, as quais realizaram o teste rápido para hepatite $B$, que resultou em $17 / 646(2,6 \%)$ reagentes que foram submetidos ao $\mathrm{HBsAg}$ por quimioluminescência. Desses, 14 (82,3\%) foram confirmados para infecção pelo HBV, evidenciando-se 2,2\% (14/646) de prevalência da infecção ativa pelo HBV na população de Porto Acre (Tabela 1). Entre os três indivíduos com resultados falsopositivos ao teste imunocromatográfico, dois adquiriram imunidade ao $\mathrm{HBV}$, provavelmente por contato prévio com o vírus (anti-HBc total e anti-HBs reagentes), e, em apenas um, O anti-HBs qualitativo (Architect ${ }^{\circledR}$, Brasil) resultou não reagente; porém, realizado o HBV-DNA quantitativo, não houve detecção de partículas virais.

Os 14 portadores da infecção ativa pelo HBV confirmados pela quimioluminescência foram não reagentes ao $\mathrm{HBeAg}$ e anti-HD total e reagentes ao anti-HBc total e anti-HBe (Tabela 1). Todos esses pacientes encontravam-se na fase de portadores inativos e foram acompanhados no SAE de Rio Branco.

Procedeu-se à quimioluminescência para anti-HBc total no soro dos 646 voluntários, dos quais 31,9\% (206/646) apresentaram reatividade a esse marcador, porém apenas 2,2\% (14/646) foram reativos ao $\mathrm{HBsAg}$, - que pode ser considerado como percentual de cronificação do HBV nessa população (Tabela 1).

A maioria dos indivíduos do total da amostra pertencia ao gênero feminino $372 / 646$ (57,6\%), e $184 / 646(28,5 \%)$ eram crianças ou adolescentes. Em decorrência de certos comportamentos de risco relação sexual desprotegida, realização de cirurgias, presença de tatuagens, uso abusivo de álcool ou drogas ilícitas - serem muito mais frequentes em pessoas a partir da adolescência, optou-se por excluir todas as crianças (101 no total) para análise relacionada à presença de $\mathrm{HBs} A g$. $\bigcirc$ uso abusivo de álcool foi a única variável relacionada à presença do HBsAg entre os 545 indivíduos avaliados (Tabela 2).

Apesar do contato prévio com o HBV ter sido maior em indivíduos nas faixas etárias mais avançadas, 9,2\% (17/184) das crianças e adolescentes incluídos na pesquisa mostraram-se reagentes ao anti-HBc total. O contato prévio com HBV também foi maior entre pessoas do gênero masculino, naquelas que relataram procedimentos cirúrgicos prévios, nas que possuíam tatuagens e nas que referiram uso abusivo de bebidas alcoólicas. Variáveis como compartilhamento de objetos de uso pessoal, relação sexual desprotegida com portador do HBV e uso de drogas ilícitas não foram relacionadas à maior reatividade ao anti-HBc total (Tabela 3 ).

\section{DISCUSSÃO}

Na Amazônia brasileira, é frequente a infecção pelo HBV, havendo acentuadas diferenças de prevalência entre as localidades ${ }^{6,8,10,12,16}$. No Brasil, a obrigatoriedade da realização de triagem sorológica para o HBV nos hemocentros, a partir de 198817, e a incorporação de testes rápidos para hepatite $B$ na atenção básica de saúde ${ }^{18}$ vêm contribuindo para o diagnóstico precoce da infecção e, consequentemente, oportunizando o acompanhamento médico especializado aos acometidos. No entanto, raramente os testes rápidos estão disponíveis às populações moradoras nos municípios do interior dos Estados brasileiros. Devido a essa restrição, e sendo a infecção pelo HBV, na maioria das vezes, totalmente assintomática ou oligossintomática, o diagnóstico é postergado e realizado quase que exclusivamente quando os portadores do HBV já desenvolveram cirrose hepática e/ou o hepatocarcinoma ${ }^{4,5}$, o que dificulta o manejo e o prognóstico desses enfermos.

Apesar das autoridades de saúde e da própria população do Acre reconhecerem que a hepatite $B$ é um grande problema de saúde pública, os dados existentes sobre a infecção pelo HBV no Estado são escassos e obtidos por meio de estudos pontuais, mostrando percentuais variáveis entre as localidades/ populações estudadas ${ }^{10,11,12}$. Devido à inexistência de estudos prévios que tenham avaliado a situação da infecção pelo HBV na população do município de Porto Acre, tornou-se impossível o comparativo temporal da situação de saúde no que tange à infecção por esse vírus naquela localidade.

Em 2012, durante a realização do estudo em Porto Acre, não havia qualquer posto de saúde ou laboratório que coletasse o soro, realizasse teste rápido ou fizesse sorologia para o HBV. Tal fato fez com que a população de Porto Acre fosse extremamente receptiva ao estudo. A busca pelo atendimento foi maior por parte das mulheres, que trouxeram os filhos, sendo de $28,5 \%$ a proporção total de crianças e adolescentes nessa amostra. Tal circunstância poderá ter levado a um viés de amostragem, resultando em uma prevalência do HBV aquém da esperada, pois outros estudos evidenciaram que o HBV é mais prevalente no gênero masculino e em faixas etárias maiores ${ }^{11,12,19}$.

Tabela 1 - Relação entre a reatividade do HBsAg e do anti-HBc total por quimioluminescência em 646 voluntários do município de Porto Acre, estado do Acre, Brasil, 2012

\begin{tabular}{|c|c|c|c|c|c|c|}
\hline \multirow{3}{*}{$\mathrm{HBsAg}$} & \multicolumn{4}{|c|}{ Anti-HBc total } & \multirow{2}{*}{\multicolumn{2}{|c|}{ Total }} \\
\hline & \multicolumn{2}{|c|}{ Reagente } & \multicolumn{2}{|c|}{ Não reagente } & & \\
\hline & $\mathrm{N}$ & $\%$ & $\mathrm{~N}$ & $\%$ & $\mathrm{~N}$ & $\%$ \\
\hline Positivo & $14^{*}$ & 6,8 & - & - & 14 & 2,2 \\
\hline Negativo & 192 & 93,2 & 440 & 100,0 & 632 & 97,8 \\
\hline Total & 206 & 31,9 & 440 & 68,1 & 646 & 100,0 \\
\hline
\end{tabular}

* Todos HBeAg não reagentes, anti-HBe reagentes e anti-HD não reagentes; Sinal convencional utilizado: - Dado numérico igual a zero, não resultante de arredondamento. 
Tabela 2 - Relação entre variáveis epidemiológicas e a reatividade ao marcador sorológico HBsAg por quimioluminescência em 545 voluntários adultos e adolescentes do munić́pio de Porto Acre, estado do Acre, Brasil, 2012

\begin{tabular}{|c|c|c|c|c|c|c|c|}
\hline \multirow{3}{*}{ Variáveis } & \multicolumn{4}{|c|}{$\mathrm{HBsAg}$} & \multirow{2}{*}{\multicolumn{2}{|c|}{ Total }} & \multirow{3}{*}{$p^{*}$} \\
\hline & \multicolumn{2}{|c|}{ Reagente } & \multicolumn{2}{|c|}{ Não reagente } & & & \\
\hline & $N$ & $\%$ & $\mathrm{~N}$ & $\%$ & $N$ & $\%$ & \\
\hline \multicolumn{8}{|l|}{ Faixa etária (anos) } \\
\hline $12-19$ & - & - & 83 & 15,6 & 83 & 15,2 & \multirow{6}{*}{0,234} \\
\hline $20-29$ & 1 & 7,1 & 80 & 15,1 & 81 & 14,8 & \\
\hline 30-39 & 2 & 14,3 & 109 & 20,5 & 111 & 20,4 & \\
\hline $40-49$ & 5 & 35,7 & 100 & 18,8 & 105 & 19,3 & \\
\hline$\geq 50$ & 6 & 42,9 & 159 & 30,0 & 165 & 30,3 & \\
\hline Subtotal & 14 & 100,0 & 531 & 100,0 & 545 & 100,0 & \\
\hline
\end{tabular}

\begin{tabular}{|c|c|c|c|c|c|c|c|}
\hline Masculino & 5 & 35,7 & 218 & 41,0 & 223 & 40,9 & 352 \\
\hline Feminino & 9 & 64,3 & 313 & 59,0 & 322 & 59,1 & כ35) \\
\hline Subtotal & 14 & 100,0 & 531 & 100,0 & 545 & 100,0 & \\
\hline
\end{tabular}

Cirurgias prévias

\begin{tabular}{lrrrrrr} 
Não & 6 & 42,9 & 312 & 58,8 & 318 & 58,3 \\
$\operatorname{Sim}$ & 8 & 57,1 & 219 & 41,2 & 227 & 41,7 \\
\hline Subtotal & 14 & 100,0 & 531 & 100,0 & 545 & 100,0
\end{tabular}

0,395

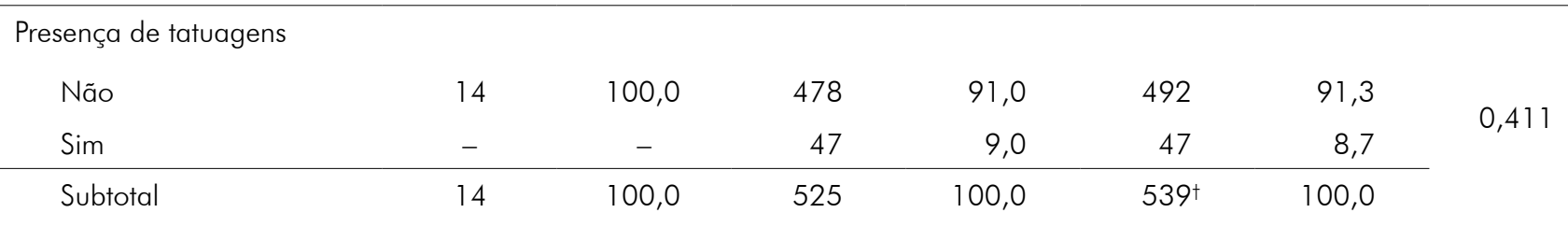

Compartilhamento de

objetos de uso pessoal

\begin{tabular}{lrrrrrrr} 
Nunca & 6 & 42,9 & 196 & 36,9 & 202 & 37,1 & \\
Sempre & 5 & 35,7 & 216 & 40,8 & 221 & 40,7 & 0,528 \\
\cline { 1 - 5 } Às vezes & 3 & 21,4 & 118 & 22,3 & 121 & 22,2 & \\
\cline { 1 - 6 } Subtotal & 14 & 100,0 & 530 & 100,0 & $544^{\ddagger}$ & 100,0 &
\end{tabular}

Relação sexual desprotegida com portador do HBV

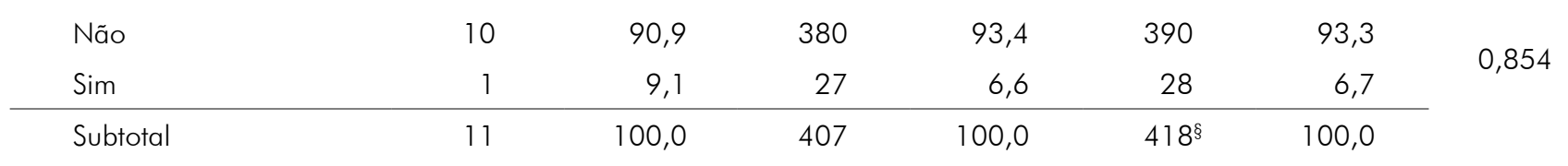

Uso de drogas ilícitas

\begin{tabular}{|c|c|c|c|c|c|c|c|}
\hline Não & 14 & 100,0 & 499 & 94,2 & 513 & 94,3 & 0570 \\
\hline Sim & - & - & 31 & 5,8 & 31 & 5,7 & ט, \\
\hline Subtotal & 14 & 100,0 & 530 & 100,0 & $544^{\ddagger}$ & 100,0 & \\
\hline
\end{tabular}

Uso abusivo de bebidas alcoólicas

\begin{tabular}{|c|c|c|c|c|c|c|}
\hline Não & 7 & 50,0 & 402 & 75,7 & 409 & 75,0 \\
\hline Sim & 7 & 50,0 & 129 & 24,3 & 136 & 25,0 \\
\hline Subtotal & 14 & 100,0 & 531 & 100,0 & 545 & 100,0 \\
\hline
\end{tabular}

* Teste qui-quadrado de Pearson; ${ }^{\dagger}$ Dado ausente na ficha de seis indivíduos; ${ }^{\ddagger}$ Dado ausente na ficha de um indivíduo; $\S$ Dado ausente na ficha de 127 indivíduos; Sinal convencional utilizado: - Dado numérico igual a zero, não resultante de arredondamento. 
Tabela 3 - Relação entre as variáveis epidemiológicas associadas ao marcador sorológico anti-HBc total em 646 voluntários do município de Porto Acre, estado do Acre, Brasil, 2012

\begin{tabular}{|c|c|c|c|c|c|c|c|}
\hline \multirow{3}{*}{ Variáveis } & \multicolumn{4}{|c|}{ Anti-HBc total } & \multirow{2}{*}{\multicolumn{2}{|c|}{ Total }} & \multirow{3}{*}{$p^{*}$} \\
\hline & \multicolumn{2}{|c|}{ Reagente } & \multicolumn{2}{|c|}{ Não reagente } & & & \\
\hline & $\mathrm{N}$ & $\%$ & $\mathrm{~N}$ & $\%$ & $\mathrm{~N}$ & $\%$ & \\
\hline \multicolumn{8}{|l|}{ Faixa etária (anos) } \\
\hline $1-10$ & 7 & 3,3 & 80 & 18,2 & 87 & 13,5 & \multirow{7}{*}{0,000} \\
\hline $11-19$ & 10 & 4,9 & 87 & 19,8 & 97 & 15,0 & \\
\hline 20-29 & 16 & 7,8 & 65 & 14,8 & 81 & 12,5 & \\
\hline 30-39 & 44 & 21,4 & 67 & 15,2 & 111 & 17,2 & \\
\hline $40-49$ & 48 & 23,3 & 57 & 12,9 & 105 & 16,3 & \\
\hline$\geq 50$ & 81 & 39,3 & 84 & 19,1 & 165 & 25,5 & \\
\hline Subtotal & 206 & 100,0 & 440 & 100,0 & 646 & 100,0 & \\
\hline
\end{tabular}

\section{Gênero}

\begin{tabular}{lrrrrrrr} 
Masculino & 108 & 52,4 & 166 & 37,7 & 274 & 42,4 & 0,000 \\
Feminino & 98 & 47,6 & 274 & 62,3 & 372 & 57,6 \\
\hline Subtotal & 206 & 100,0 & 440 & 100,0 & 646 & 100,0 & \\
\hline
\end{tabular}

\section{Cirurgias prévias}

$\begin{array}{lrrrrrrr}\text { Não } & 117 & 56,8 & 298 & 67,7 & 415 & 64,2 & 0,007 \\ \text { Sim } & 89 & 43,2 & 142 & 32,3 & 231 & 35,8 & 100,0\end{array}$

Presença de tatuagens

\begin{tabular}{lrrrrrrr} 
Não & 188 & 94,5 & 304 & 89,4 & 492 & 91,3 & 0,044 \\
Sim & 11 & 5,5 & 36 & 10,6 & 47 & 8,7 & 100,0 \\
\hline Subtotal & 199 & 100,0 & 340 & 100,0 & $539+$ & \\
\hline
\end{tabular}

Compartilhamento de objetos de uso pessoal

\begin{tabular}{lrrrrrrr} 
Nunca & 80 & 38,8 & 158 & 36,1 & 238 & 37,0 & 41,1 \\
Sempre & 77 & 37,4 & 188 & 42,9 & 265 & 0,400 \\
Às vezes & 49 & 23,8 & 92 & 21,0 & 141 & 21,9 \\
\hline Subtotal & 206 & 100,0 & 438 & 100,0 & $644^{\ddagger}$ & 100,0 \\
\hline
\end{tabular}

Relação sexual desprotegida com portador do HBV

\begin{tabular}{lrrrrrrr} 
Não & 150 & 93,2 & 340 & 95,2 & 490 & 94,6 & 0,335 \\
Sim & 11 & 6,8 & 17 & 4,8 & 28 & 5,4 & 100,0 \\
\hline Subtotal & 161 & 100,0 & 357 & 100,0 & 518 \$ & & \\
\hline Uso de drogas ilícitas & & & & & & & \\
Não & 198 & 96,1 & 416 & 94,8 & 614 & 4,2 & 0,453 \\
Sim & 8 & 3,9 & 23 & 5,2 & 31 & 100,0
\end{tabular}

Uso abusivo de bebidas alcoólicas

\begin{tabular}{lrrrrrrr} 
Não & 138 & 67,0 & 372 & 84,5 & 510 & 78,9 & 0,000 \\
Sim & 68 & 33,0 & 68 & 15,5 & 136 & 21,1 \\
\hline Subtotal & 206 & 100,0 & 440 & 100,0 & 646 & 100,0
\end{tabular}

* Teste qui-quadrado de Pearson; ${ }^{\dagger}$ Dado ausente na ficha de seis indivíduos; ${ }^{\ddagger}$ Dado ausente na ficha de dois indivíduos; ${ }^{\S}$ Dado ausente na ficha de 127 indivíduos; " Dado ausente na ficha de um indivíduo. 
Em Porto Acre, os dados mostraram a existência de infecção passada pelo HBV em 29,7\% (192/646), havendo infecção atual pelo vírus em 2,2\% (14/646), o que caracteriza uma endemicidade intermediária baixa (2-4\%) em relação a outras regiões do mundo ${ }^{3}$; e ainda menor que a verificada em estudos prévios efetivados em outros municípios acreanos, que obtiveram em média $3,3 \%$ de soropositividade ao $\mathrm{HBsAg}^{10,12}$. Esse fato pode estar relacionado ao viés de amostragem ou, ainda, ao fato de que Porto Acre nunca teve hospitais, portanto nesse município não houve possíveis transmissões do HBV por transfusão de sangue braço a braço (ausência de exames sorológicos); sendo que, nos municípios do interior do estado do Acre, essa prática foi comum até o ano de 1998, quando foram implantadas as unidades hemoterápicas.

No estado do Pará, a infecção ativa pelo HBV foi encontrada em 3,6\%, porém não houve referência quanto aos municípios avaliados, sendo esta a média geral das amostras analisadas pelo Lacen do Pará?. Pereira et al. ${ }^{19}$ conduziram um estudo multicêntrico incluindo pessoas entre 13 e 69 anos de idade em nove capitais da Região Nordeste brasileira, três capitais da Região Centro-Oeste, além do Distrito Federal, e detectaram infecção ativa pelo HBV em menos de $1 \%$ nos indivíduos não vacinados. Aparentemente, apesar de haver um número maior de vacinados na Região Norte do país, o índice de infecção ativa ou prévia demonstra a maior transmissão viral nessa populaçãó .

A frequência do marcador de contato para HBV também foi bastante elevada (31,9\%) em Porto Acre, muito semelhante à de outros estados da Região Norte, como o Pará, onde foi detectada reatividade em $37,7 \%$ dos entrevistados 9 , e em localidades ribeirinhas de Porto Velho, Rondônia, onde se detectou $32,1 \% 20$. Entretanto, neste estudo, os percentuais de reatividade ao anti-HBc total foram menores que os resultantes de estudos anteriores realizados no Acre ${ }^{10,11,12}$, que obtiveram prevalência de $40,2^{10}$ e $61,5 \%{ }^{12}$. Talvez tal fato possa ser explicado pela ampliação da cobertura vacinal no Acre a partir de 1999. Sedimentando essa possibilidade, Lindenberg et al. ${ }^{21}$ mostraram que houve um decréscimo na prevalência de hepatite $B$ nos últimos 10 anos em doadores de sangue em Campo Grande, estado do Mato Grosso do Sul, e apontaram as campanhas de vacinação como a principal causa para se explicar o achado.

$\mathrm{Na}$ Região Amazônica brasileira, alguns pesquisadores mostraram a importância da transmissão familiar ou horizontal do $\mathrm{HBV}^{13,22}$. O risco da transmissão horizontal e vertical do HBV é maior em recém-nascidos de mães com $\mathrm{HBeAg}$ positivo e varia de $70 \%$ a $90 \%$ aos 6 meses de idade. Cerca de $90 \%$ dessas crianças permanecerão cronicamente infectadas. Nos casos de mães $\mathrm{HBeAg}$ negativas, - risco da infecção perinatal entre os recémnascidos varia de $10 \%$ a $40 \%$, com risco de $40 \%$ a $70 \%$ dessas crianças tornarem-se cronicamente infectadas $^{23}$. contato com o HBV aumenta conforme a faixa etária, o que é plenamente evidenciado na literatura médica6,14,24,25. Em Porto Acre, um dado de extrema relevância foi a detecção do anti-HBc total em 9,2\% $(17 / 184)$ das crianças e adolescentes incluídos no estudo, evidenciando o contato precoce com o HBV, fato antes comprovado por Lobato et al. ${ }^{13}$, que evidenciaram a presença do HBV em menores de 1 ano de idade nascidos de mães portadoras do vírus. No Pará, Aquino et al. ${ }^{9}$ detectaram $6,9 \%$ de reatividade ao marcador de contato para HBV em menores de 19 anos. As pessoas que se submeteram previamente à cirurgia apresentaram maior reatividade ao marcador de contato do HBV, pois, durante as cirurgias, a transmissão do HBV pode ser feita por meio de materiais não esterilizados e ainda pelas hemotransfusões a que os pacientes podem ser submetidos. Diversos estudos com anti-HBc total isolado evidenciaram infecção pós-transfusão de hemoderivados, com taxas de infectividade alcançando $17 \% 26,27$

Em relação ao gênero, foi verificado maior percentual de anti-HBc total reagente em indivíduos masculinos, fato bastante sedimentado por outros pesquisadores ${ }^{25,28}$. Essa associação pode ser decorrente da maior exposição em virtude de relações sexuais desprotegidas, hipótese que é reforçada pela maior prevalência de outras doenças sexualmente transmissíveis nesse gênero ${ }^{29}$.

O uso de bebidas alcoólicas de forma abusiva se relacionou tanto ao marcador de exposição ao vírus quanto aos portadores de infecção ativa pelo HBV. Esse hábito, na verdade, é considerado de risco também para a aquisição de outras doenças consideradas sexualmente transmissíveis ${ }^{29}$. $\bigcirc$ etilismo é mais comum entre os indivíduos do gênero masculino e contribui para acelerar o processo de cirrose hepática e hepatocarcinoma em portadores de hepatite $B$ crônica ${ }^{30,31}$.

\section{CONCLUSÃO}

A prevalência da infecção pelo HBV em Porto Acre evidencia a gravidade da situação, visto que um terço da amostra do estudo já entrou em contato com o vírus, valor provavelmente subestimado, dado que $28,5 \%$ foi composta por crianças e adolescentes que, normalmente, são grupos menos acometidos.

Levando-se em consideração que a amostra deste estudo foi de conveniência, havendo grande participação feminina e ainda de crianças e adolescentes, e que trabalhos anteriores mostraram que a infecção por HBV ocorre com maior frequência em indivíduos adultos do gênero masculino, acredita-se que um estudo de base populacional poderia detectar uma prevalência de infecção pelo HBV ainda maior nessa população.

Essa situação reforça a ideia de que há necessidade de avaliação dos programas de vacinação contra o HBV no Município, assim como da implementação de políticas que sirvam para reduzir a transmissão desse vírus nessa população. 


\section{AGRADECIMENTOS}

Aos acadêmicos e egressos do curso de medicina da Universidade Federal do Acre (UFAC): Alex Sandro Souza Almeida, Angela Maria de Amorim Sózio, Danielle Brandão Nascimento, Conceição Maria Diniz Castelo Branco Pereira, Sidnei Umberto Bertholdi Filho, Jéssica Sydrião dos Santos, Elizabeth de Souza Piccirilli e Lukas Vieira de Lima e Athos Muniz Braña.

À Secretaria de Saúde do Estado do Acre, em especial à Izanelda Batista Magalhães, Alissandra
Araúio dos Santos, Amarildo Henrique Rose Cruz, Manoel Pereira Filho, José Waldek de Oliveira Leitão e José Seixas Leal.

Ao Secretário de Saúde e funcionários da Secretaria Municipal de Saúde de Porto Acre, que contribuíram na pesquisa.

\section{APOIO FINANCEIRO}

Conselho Nacional de Desenvolvimento Científico e Tecnológico, Programa de Pesquisa para o SUS (PPSUS) e Secretaria de Saúde do Estado do Acre.

\section{REFERÊNCIAS}

1 World Gastroenterology Organisation. World Gastroenterology Organisation global guideline: hepatitis B. Milwaukee: WGO; 2015.

2 World Health Organization. Guidelines for the prevention, care and treatment of persons with chronic hepatitis B infection. Geneva: WHO; 2015.

3 Ott JJ, Stevens GA, Groeger J, Wiersma ST. Global epidemiology of hepatitis $B$ virus infection: new estimates of age-specific $\mathrm{HBsAg}$ seroprevalence and endemicity. Vaccine. 2012 Mar;30(12)2212-9.

4 leluzzi D, Covolo L, Donato F, Fattovich G. Progression to cirrhosis, hepatocellular carcinoma and liver-related mortality in chronic hepatitis B patients in Italy. Dig Liver Dis. 2014 May;46(5):427-32.

5 Sundquist K, Sundquist J, Ji J. Risk of hepatocellular carcinoma and cancers at other sites among patients diagnosed with chronic hepatitis B virus infection in Sweden. J Med Virol. 2014 Jan;86(1): 18-22.

6 Universidade de Pernambuco. Estudo de prevalência de base populacional das infecções pelos vírus das hepatites $A, B$ e $C$ nas capitais do Brasil. Recife (PE): UPE; 2010. 295 p.

7 Bensabath G, Boshell J. Presença do antígeno "Austrália" (Au) em populações do interior do Estado do Amazonas - Brasil. Rev Inst Med Trop Sao Paulo. 1973 set-out; 15(5):284-8.

8 Braga WSM, Castilho MC, Borges FG, Martinho ACS, Rodrigues IS, Azevedo EP, et al. Prevalence of hepatitis $B$ virus infection and carriage after nineteen years of vaccination program in the Western Brazilian Amazon. Rev Soc Bras Med Trop. 2012 Jan-Feb;45(1):13-7.

9 Aquino JA, Pegado KA, Barros LP, Machado LFA. Soroprevalência de infecções por vírus da hepatite $B$ e vírus da hepatite $C$ em indivíduos do Estado do Pará. Rev Soc Bras Med Trop. 2008 julago;4 1 (4):334-7.
10 Tavares-Neto J, Almeida D, Soares MC, Uchoa R, Viana S, Darub R, et al. Seroprevalence of hepatitis $B$ and $C$ in the Western Brazilian Amazon region (Rio Branco, Acre): a pilot study carried out during a hepatitis B vaccination program. Braz J Infect Dis. 2004 Apr;8(2):133-9.

11 Silva RSU, Ribeiro SAL, Silveira RP, Freitas MS. Avaliação da pré-triagem sorológica para o marcador do vírus da hepatite B (anti-HBc total) em candidatos à doação de sangue no Estado do Acre, 2002. Rev Soc Bras Med Trop. 2006 mar-abr;39(2):179-82.

12 Viana S, Paraná R, Moreira RC, Compri AP, Macedo $V$. High prevalence of hepatitis $B$ virus and hepatitis D virus in the Western Brazilian Amazon. Am J Trop Med Hyg. 2005 Oct;73(4): 808-14.

13 Lobato C, Tavares-Neto J, Rios-Leite M, Trepo C, Vitvitski L, Parvaz $P$, et al. Intrafamilial prevalence of hepatitis B virus in Western Brazilian Amazon region: epidemiologic and biomolecular study. J Gastroenterol Hepatol. 2006 May;21(5): 863-8.

14 Nakashima JP, Koifman S, Koifman RJ. Tendência da mortalidade por neoplasias malignas selecionadas em Rio Branco, Acre, Brasil, 19802006. Cad Saude Publica. 2011 jun;27(6): $1165-74$.

15 Instituto Brasileiro de Geografia e Estatística. Cidades@: Porto Acre [Internet]. Rio de Janeiro: IBGE; 2012 [citado 2010 abril 15]. Disponível em: https://cidades.ibge.gov.br/v4/brasil/ac/porto-acre/ panorama.

16 Vieira GD, Florão M, Castro KPO, Alves TC, Vaiciunas S, Honda ER, et al. Hepatitis B in Rondônia (Western Amazon Region, Brazil): descriptive analysis and spatial distribution. Arq Gastroenterol. 2015 Jan-Mar;52(1): 18-21. 
17 Brasil. Lei $n^{\circ} 7.649$ de 25 de Janeiro de 1988. Estabelece a obrigatoriedade do cadastramento dos doadores de sangue, bem como a realização de exames laboratoriais no sangue coletado, visando a prevenir a propagação de doenças, e dá outras providências. Diário Oficial da União, Brasília (DF), 1988 jan 27; Seção 1:1609.

18 Ministério da Saúde (BR). Secretaria-Executiva. Ministério da Saúde e municípios: juntos pelo acesso integral e de qualidade à saúde. 2. ed. Brasília: Ministério da Saúde: 2013. 70 p.

19 Pereira LMMB, Martelli CMT, Merchán-Hamann E, Montarroyos UR, Braga MC, Lima MLC, et al. Population-based multicentric survey of hepatitis $B$ infection and risk factor differences among three regions in Brazil. Am J Trop Med Hyg. 2009 Aug;81 (2):240-7.

20 Silva ACB, Souza LFB, Katsuragawa TH, Lima AA, Vieira DS, Salcedo JMV. Perfil soroepidemiológico da hepatite $B$ em localidades ribeirinhas do rio Madeira, em Porto Velho, Estado de Rondônia, Brasil. Rev Pan-Amaz Saude. 2015 jun;6(2):51-9.

21 Lindenberg ASC, Motta-Castro ARC, Puga MA, Tanaka TSO, Torres MS, Fernandes-Fitts SM, et al. Decrease in hepatitis B prevalence among blood donors in Central-West Brazil. J Venom Anim Toxins Incl Trop Dis. 2013 Apr; 19:7.

22 Brasil LM, Fonseca JCF, Souza RB, Braga WSM, Toledo LM. Prevalência de marcadores para o vírus da hepatite B em contatos domiciliares no Estado do Amazonas. Rev Soc Bras Med Trop. 2003 setout;36(5):565-70.

23 McQuillan GM, Coleman PJ, Kruszon-Moran D, Moyer LA, Lambert SB, Margolis HS. Prevalence of hepatitis B virus infection in the United States: the National Health and Nutrition Examination Surveys, 1976 through 1994. Am J Public Health. 1999 Jan;89(1):14-8.
24 Abdullah SM. Prevalence of hepatitis B and C in donated blood from the Jazan Region of Saudi Arabia. Malays J Med Sci. 2013 Mar;20(2):41-6.

25 Ting-Lu Z, Zhi-Ping X, Hong-Yu L, Chang-Hong G, Liang $Y$, Qiang $D$, et al. A community-based seroepidemiological study of hepatitis B infection in Lianyungang, China, 2010. Western Pac Surveill Response J. 2012 Jul-Sep;3(3):69-75.

26 Allain JP. Occult hepatitis B virus infection: implications in transfusion. Vox Sang. 2004 Feb;86(2):83-91.

27 Zanetti AR, Romanò L, Zappá A, Velati C. Changing patterns of hepatitis $B$ infection in Italy and NAT testing for improving the safety of blood supply. J Clin Virol. 2006 May;36(1):S51-5.

28 Machado DFGP, Martins T, Trevisol DJ, Vieira e Silva RA, Narciso-Schiavon JL, Trevisol FS, et al. Prevalence and factors associated with hepatitis B virus infection among senior citizens in a Southern Brazilian city. Hepat Mon. 2013 Apr;13(5):e7874.

29 Da Ros CT, Schmitt CS. Global epidemiology of sexually transmitted diseases. Asian J Androl. 2008 Jan;10(1):1 10-4.

30 Grob P, Jilg W, Bornhak H, Gerken G, Gerlich W, Günther $S$, et al. Serological pattern "anti-HBC alone": report on a workshop. J Med Virol. 2000 Dec;62(4):450-5.

31 Chachá SGF, Ferreira SC, Costa TV, Almeida Filho LC, Villanova MG, Souza FF, et al. Clinical, demographic and epidemiological characteristics of patients with hepatitis B followed at a university hospital in southeastern Brazil: predominance of $\mathrm{HBeAg}$ negative cases. Rev Soc Bras Med Trop. 2011 Jan-Feb;44(1):13-7. 